MATEC Web of Conferences 22,04027 (2015)

DOI: $10.1051 /$ matecconf/ 20152204027

(C) Owned by the authors, published by EDP Sciences, 2015

\title{
A Framework Study of Bohai Sea Ice Comprehensive Service and Ex- pert Aid Decision-making System
}

\author{
Xifang Jin, Donglin Guo*, Shuo Wang, Xiangyu Zhao, Yan Song \& Aichao Liu \\ tion, Qingdao, Shandong, China \\ North Sea Marine Forecast Center of State Oceanic Administration, Qingdao, Shandong, China \\ Wenfei Jiang \\ North China Sea Data \& Information Service of SOA, Qingdao, Shandong, China \\ Ruifu Wang \\ Shandong University of Science and Technology, Qingdao, Shandong, China
}

Shandong Provincial Key Laboratory of Marine Ecological Environment and Disaster Prevention and Mitiga-

Xiaomin Li

First Institute of Oceanography, State Oceanic Administration, Qingdao, Shandong, China

\begin{abstract}
In this paper, we propose an overall framework about Bohai sea ice comprehensive service and expert aid decision-making system, among which six subsystems consists of sea ice multi-source information acquisition subsystem, sea ice comprehensive information database, sea ice comprehensive information integration subsystem, sea ice expert aid decision-making subsystem, sea ice products release subsystem, and sea ice disaster loss evaluation subsystem. The proposing system has such features as functional integration, business-oriented product services, visual display and decision making, and so on. This paper can provide reference for the construction of sea ice comprehensive service and expert aid decision-making system in China.
\end{abstract}

Keywords: sea ice; comprehensive service; aid decision-making; system framework

\section{INTRODUCTION}

In the winter of $2009 / 2010$, the most serious sea ice in Bohai Sea and north of Yellow Sea happened. 51 percent of the whole Bohai Sea and 93 percent of Liaodong Gulf were covered by sea ice during the period of severe ice. Simultaneously, the sea ice edge of Laizhou Gulf reached 46 nautical miles, which became the maximum of 40 years. The occurrence of severe sea ice disaster not only threatens the safety of people's life and property, but also seriously constrains the activities such as all kinds of oceanic production, marine oil exploitation, marine transportation and sea fishing and so on. Therefore, it is necessary and particularly urgent to enhance ability in sea ice safety insurance, improve and perfect sea ice monitoring and forecasting service system, and develop our own sea ice comprehensive service platform to greatly cut losses in economy and people's life and property.

In this paper, we propose an overall framework about sea ice comprehensive service and expert aid decision-making system, which provides a reference for the building of sea ice comprehensive service and expert aid decision-making system of our nation.

\section{SEA ICE COMPREHENSIVE SERVICE AND EXPERT AID DECISION-MAKING SYSTEM FRAMEWORK}

In recent years, foreign researchers have deeply researched the building of sea ice forecast and comprehensive information integration systems (Karvonen 2012, William 2005, Wenyang 2009 \& Scott 2010). Meanwhile, some researchers have also studied in expert aid decision-making systems (Shiway et al. 2014). Domestic scholars have explored in sea ice satellite remote sensing monitoring system (Ning 2011, Qiaozhen 2007, Haitian 2011 \& Song 2014), sea ice on-board monitoring system (Shuo et al. 2013), sea ice radar monitoring system (Meng 2005, Jingkun 2006 \& Yaoqing 2013) and business-oriented numerical sea ice prediction system (Conghua et al. 2013) and have achieved some gratifying results. Based on above studies and faced with the current work of Bohai sea ice business-oriented disaster prevention and reduction, we propose that it is essential to build a data processing flow of "data requisition-data analysis-information integration-comprehensive service", and we should comprehensively use the technique achievements in sea ice three-dimensional monitoring, high-precision numerical sea ice prediction, expert assistant and sea ice disaster loss evaluation. The aim

*Corresponding author: eva1004@163.com

This is an Open Access article distributed under the terms of the Creative Commons Attribution License 4.0, which permits unrestricted use, distribution, and reproduction in any medium, provided the original work is properly cited. 
system consists of six subsystems: sea ice multi-source information acquisition subsystem, sea ice comprehensive information database, sea ice comprehensive information integration subsystem, sea ice expert aid decision-making subsystem, sea ice products release subsystem and sea ice disaster loss evaluation subsystem.

The general structure of sea ice comprehensive service and expert aid decision-making system is shown in Figure 1.

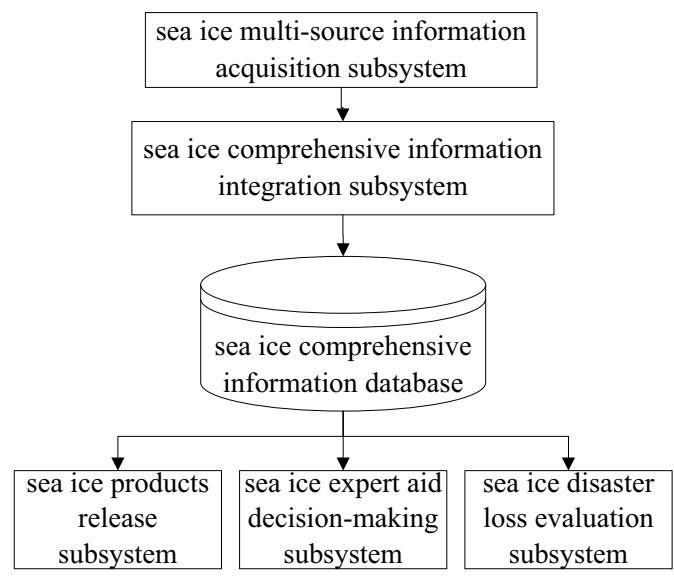

Figure 1. The general structure of sea ice comprehensive service and expert aid decision-making system

\subsection{Sea ice multi-source information acquisition subsystem}

Based on the dedicated data transmission network, all data products of three-dimensional sea ice emerging monitoring system integrating data of satellite, air plane, shore-based or island-based monitoring, buoy, on-board mobile monitoring and $\mathrm{x}$-band radar and products of numerical sea ice prediction system will be integrated to terminal computers in the same network segment to realize the quick acquisition and transmission of sea ice comprehensive information of business-oriented and emergency work. Sea ice multi-source information are transmitted from acquisition point to terminal computers in one network segment by satellite, dedicated data transmission network, web or disks.

The logical structure of sea ice multi-source information acquisition subsystem is shown in Figure 2.

\subsection{Sea ice comprehensive information database}

Sea ice comprehensive information database stores all related information of sea ice monitoring, sea ice forecast and alert, sea ice loss evaluation and aid decision making. There are three benefits for building of the dedicated database. First, it could provide essential monitoring, forecast and alert information for man- agement department and the public. Secondly, it provides related decision aided information for the sea ice disaster emergency and decision. Thirdly, it would provide historical materials and other data support for sea ice loss evaluation. The database includes six types of sea ice data:

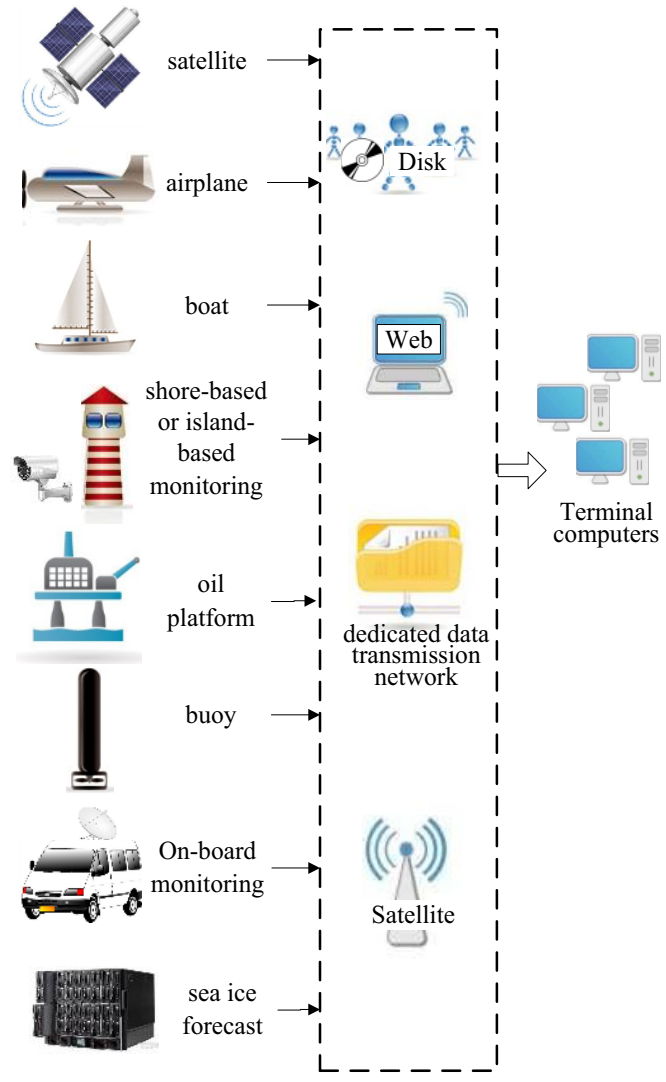

Multi-source sea ice information

Data transmission mode

Figure 2. The logical structure of sea ice multi-source information acquisition subsystem

(1) Bohai space foundational geographic information including coastal land foundational geographic data and the electronic chart of Bohai Sea;

(2) Sea ice monitoring data from satellite monitoring, air plane monitoring, shore-based and island-based monitoring, ice detecting buoy, on-board mobile monitoring, ice detecting boat and $\mathrm{x}$-band radar monitoring and so on;

(3) Sea ice forecasting data of short-term forecast, middle and long term forecast, sea ice alert information and numerical sea ice prediction data predicting features of sea ice thickness, ice intensity and ice drift velocity;

(4) Environmental sensitive areas consist of marifarms, oil platforms, coastal ports and other areas possibly polluted; 
(5) Aid decision-making information including Ice rescue equipment and human resources of coastal ports, contact Information of marine and fishery departments, and possible rescuing measures of different sea ice levels and so on;

(6) Historical sea ice information and disaster loss evaluation information storing sensitive area disaster in severe ice year and all disaster loss evaluation data.

The constitution of sea ice comprehensive information database is shown in Figure.3.

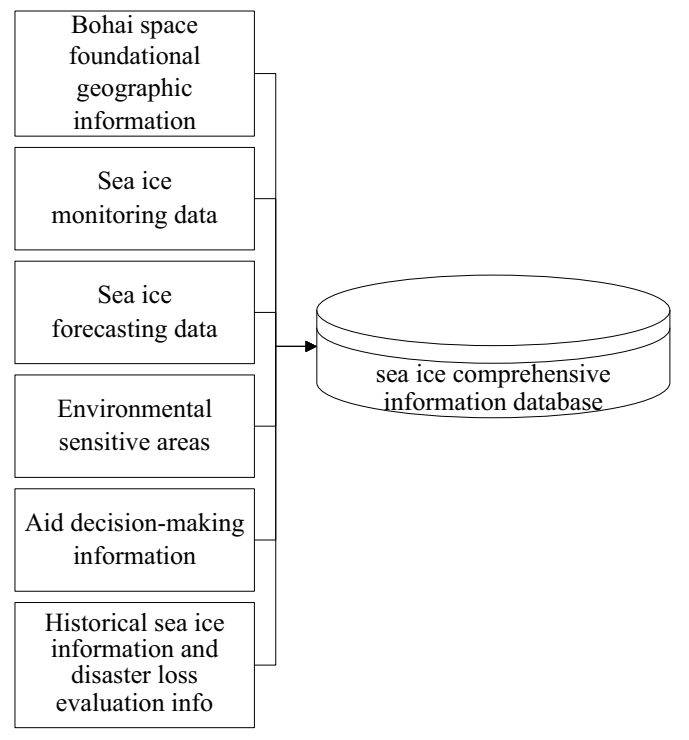

Figure 3. The constitution of sea ice comprehensive information database

\subsection{Sea ice comprehensive information integration subsystem}

Using data integration technique based on heterogeneous systems, the subsystem could realize the data processing of multi-format parsers, data transformation, quality control and near real-time storage for multi-source, multi-scale and multi-time sea ice monitoring data and forecasting and alert information from information acquisition subsystem. The business-oriented data flow chart of the sea ice comprehensive information integration subsystem is shown in Figure.4.

The subsystem contains four function modules as follows:

(1)Making data format specification based on spatial data storage

Make a series of data storage format specification meeting visual requirement of GIS system platform for involving sea ice monitoring and forecasting and alert data, which is helpful for keeping accordance of data storage and visualization.

(2)Multi-format parsers and transformation for sea ice comprehensive information
Analyze the original acceptance data format and the aiming data storage format to realize classified analysis for all original data of multi-source, multi-scale and multi-time sea ice monitoring data and forecast and alert information acquired from the acquisition subsystem. Based on heterogeneous data processing technique, develop different data processing programs for transforming the multi-format parser data to spatial data format used in comprehensive service database.

The logical structure of data integration design based on heterogeneous systems is shown in Figure.5.

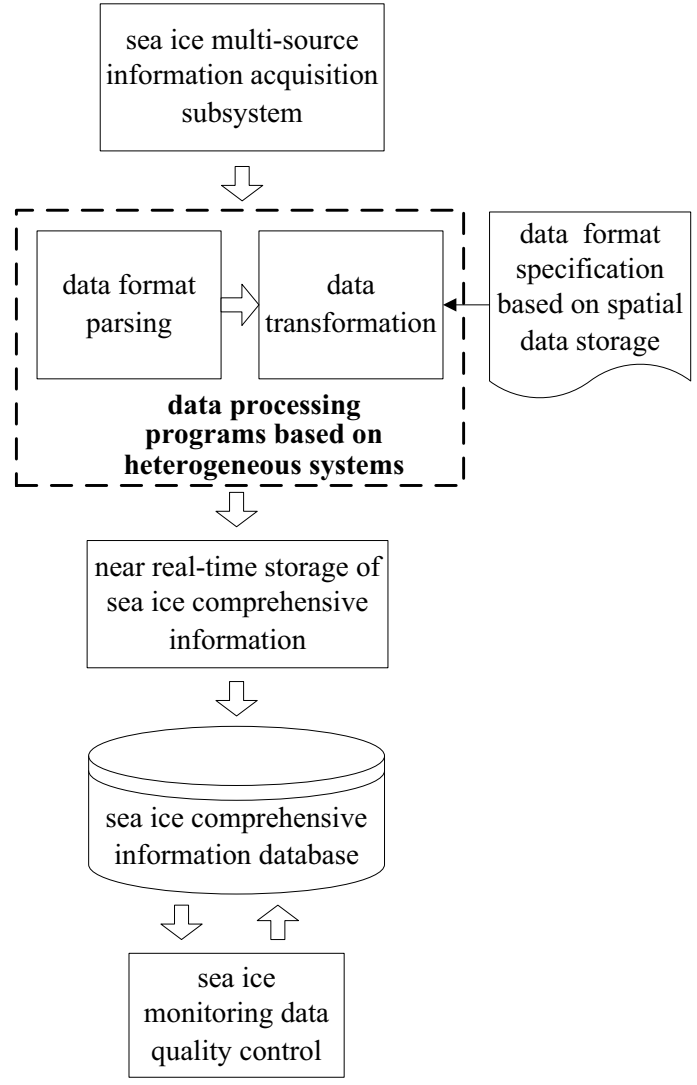

Figure 4. The business-oriented data flow chart of the sea ice comprehensive information integration subsystem

(3)Near real-time storage of sea ice comprehensive information

After operations of acquisition, analysis and data transformation, the system can immediately store all referring data in sea ice comprehensive information database.

(4)Sea ice monitoring data quality control

In condition that we cannot ensure all monitoring data are qualified, data quality control based on some quality control standards is essential for making sure good service and right decisions.

Make data quality standard based on sea ice monitoring data standard and historical data of Bohai sea ice monitoring work. Based on some methods for data 
quality control such as minimum and maximum value check, the internal accordance check, threshold value check, the aiming system can give some amending tips for some serious problems affecting the quality of sea ice monitoring data, and then business specialists can analyze and mark the error data with their own experiments. By doing this, the quality of the sea ice monitoring data to database can be ensured. All data are still stored in the database after being marked or amended.

\subsection{Sea ice expert aid decision-making subsystem}

Based on sea ice emergency plans for coastal ports, oil platforms and marifarms, the subsystem selects decision support data from sea ice comprehensive service database and provides sea ice aid decision-making scheme for sea ice disaster and accident emergency. Simultaneously, this subsystem provides functions for drawing path and outputting pictures in specified position and for definite size. The business-oriented data flow chart of the sea ice expert aid decision-making subsystem is shown in Figure 5.

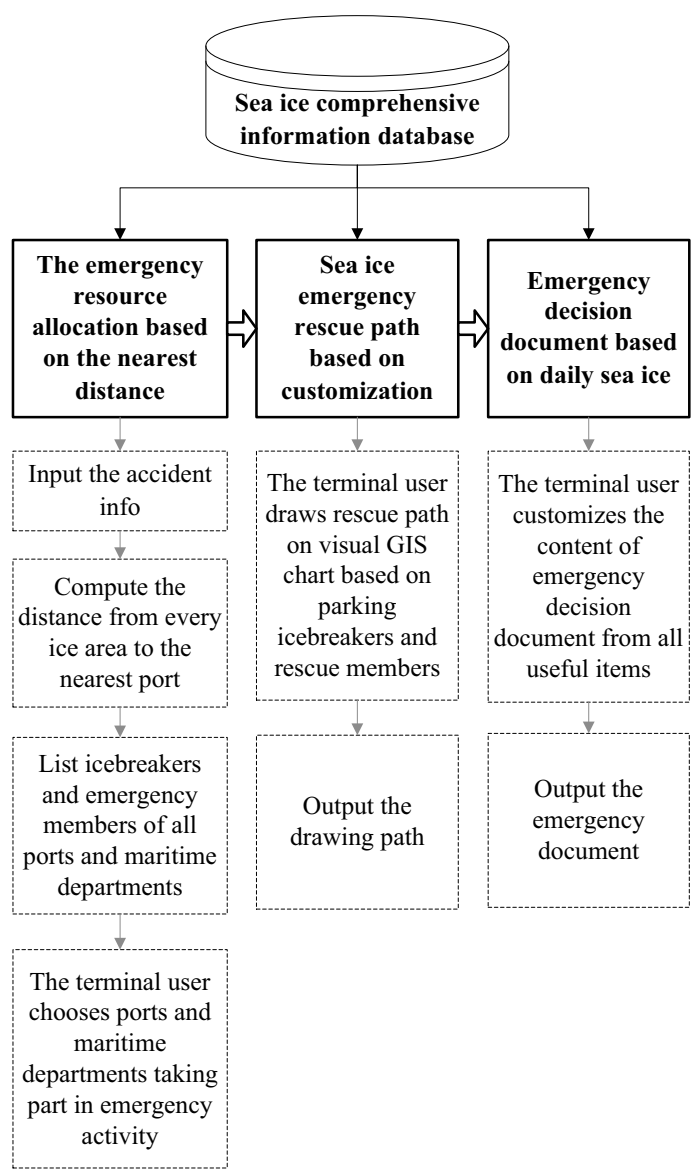

Figure 5. The business-oriented data flow chart of the sea ice expert aid decision-making subsystem
The subsystem contains three function modules as follows:

(1)The emergency resource allocation based on the nearest distance

Based on the daily ice monitoring information, this module would compute the distance between every ice area and all coast ports, and show the distance from ice areas to the nearest ports on visual GIS chart. If users need rescue an accidental boat in a specified position on electronic chart, the subsystem would show an interface for collecting accident information containing accident position and the trapped people and boat information, then the subsystem would compute the distance between disaster position and all coast ports, and offer the useful emergency equipment and humans list of three ports in nearest distance to the accident position.

(2)Sea ice emergency rescue path based on customization

This module should offer functions for customizing the emergency rescue path, in which users could draw the rescue path from the specified ports to disaster positions on visual GIS platform by means of interactively drawing and rendering based on ports and the disaster positions. Additionally, the program also provides interface for outputting picture and coordinate of user's customized rescue path.

\section{Emergency decision document}

1. Elaborate Relations between every ice area and its nearest coast port by list the distance and center ice thickness of every ice area in forms of table and graph.

2. State the incident info need to be rescued.

3. List icebreakers and emergency members of the nearest 3 ports to the accident place.

4. The customized rescue path coordinate and picture.

5. The decision support scheme based on sea ice alert level and rescue type.

6. Other interpretation and pictures.

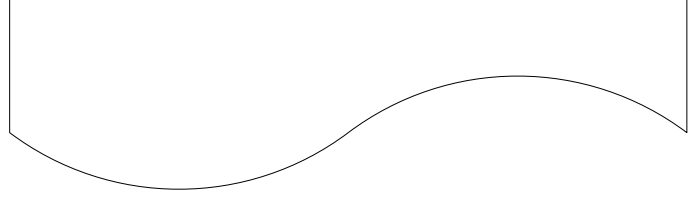

Figure 6. The structure of the emergency decision document

(3)Emergency decision document based on daily sea ice

The subsystem output customizes decision docu- 
ments based on the module of emergency resource allocation and emergency rescue path drawing. In this function module, VBA component is used by adding a reference to Microsoft.Office.Interop.Word.dll, and the subsystem realizes the changes of document in specified location or having specified content, fills the decision analysis results in words, pictures or tabular form to decision document.

The structure of the emergency decision document is shown in Figure 6.

\subsection{Sea ice products release subsystem}

Based on the WebGIS platform, this module realizes functions for business-oriented management departments releasing information of sea ice forecasting and alert reports to the public. This module contains functions as near real-time release and query of sea ice forecasting and alert information and aid decision-making information, and GIS visualization of sea ice information.

\subsection{Sea ice disaster loss evaluation subsystem}

Based on historical sea ice disasters, we can build mathematical models for loss evaluation of ports and transportation, oil platforms and marifarms in ice disaster. This function module will use these models to do sea ice loss evaluation after yearly sea ice.

\section{SYSTEM REALIZATION AND FEATURES}

This paper uses the suggested system framework, exemplarily develops Bohai sea ice comprehensive service and expert aid decision-making system using Visual Studio and ArcGIS developing platform and oracle database. We integrate and store all data of satellite monitoring, on-board and oil platform radar monitoring, buoy monitoring, shore-based and island-based manual monitoring, and sea ice middle and long term and numerical forecast in sea ice comprehensive spatial database and show them on one platform. In addition, we collect and process decision-making documents in marifarms, coastal ports, oil platforms and maritime departments, further customizes and outputs sea ice emergency decision-making document based on sea ice levels. At last, publish sea ice comprehensive service information and forecast to the public.

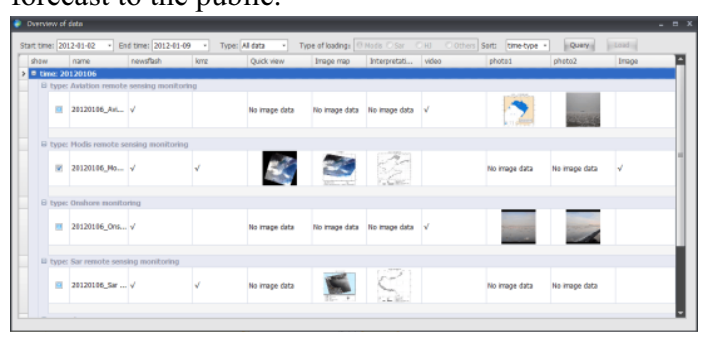

Figure 7. A query list of choosing sea ice comprehensive service information

Several screenshots of Bohai sea ice comprehensive service and expert aid decision-making system exemplary built in this paper is shown in Figure 7 to Figiure 11.

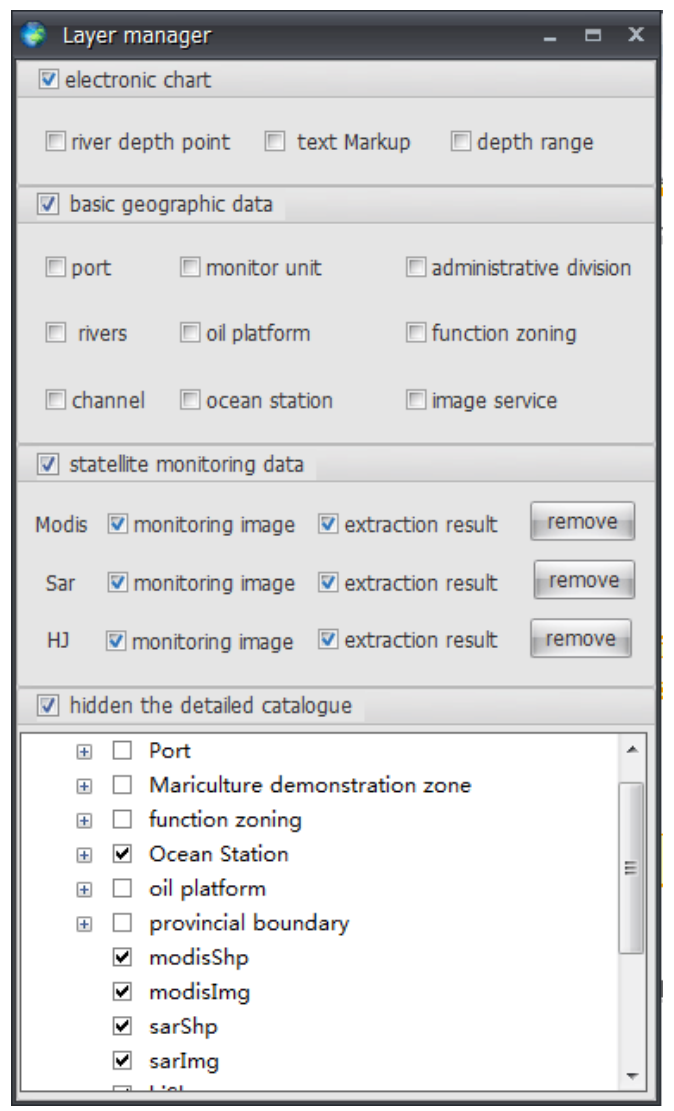

Figure 8. Layer manager interface of system platform 


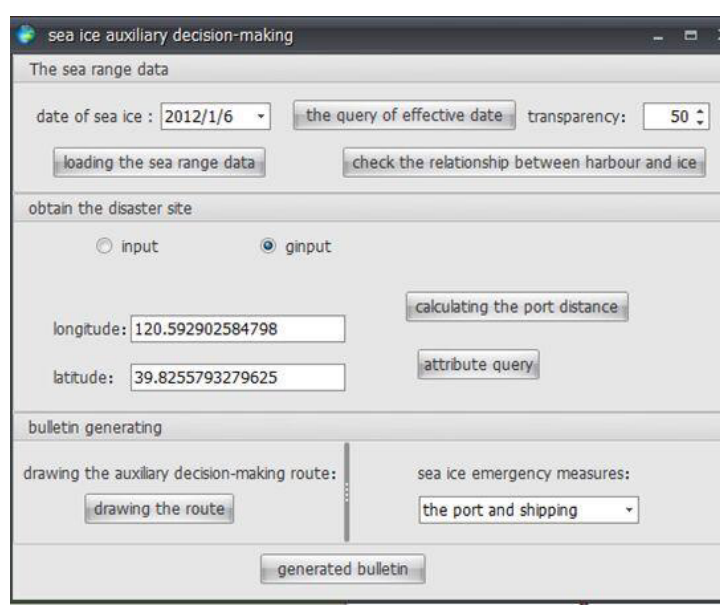

Figure 9. The customization interface of sea ice aid decision-making function

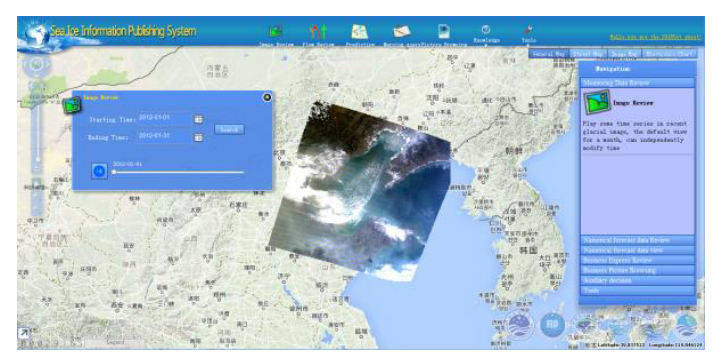

Figure 10. The satellite monitoring information in sea ice public-oriented publishing system

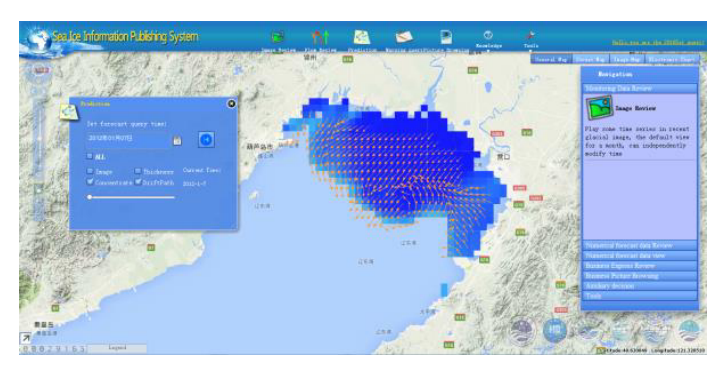

Figure 11. The sea ice forecasting information in sea ice public-oriented publishing system

Bohai sea ice comprehensive service and expert aid decision-making system has features are as follows:

(1) It has comprehensive functions. This system involves every aspect in sea ice monitoring, sea ice forecast and alert, sea ice loss evaluation and emergency decision, and realizes the information integration and GIS visualization of the integration info.

(2) Based on all data in sea ice business-oriented monitoring and sea ice forecast, the system builds the data processing flow of "data acquisition-data analysis-information integration-comprehensive service" and sea ice business-oriented service mode.

(3) Based on techniques of GIS and Webservice, the aiming system realizes three main functions as comprehensive sea ice data integration, data visualization on GIS platform and comprehensive decision making based on a visual platform.

The aiming system services for business-oriented management departments of sea ice monitoring and sea ice forecast, fishery departments possibly suffering from sea ice disaster, coast ports and transportation departments and maritime departments, which provides sea ice service information and decision information.

\section{CONCLUSION}

Based on current situation of Bohai sea ice monitoring and forecasting and alert service, we propose a general framework's design of sea ice comprehensive service and expert aid decision-making system, which provides services for oceanic production, marine oil exploitation, marine transportation, and other business-oriented management. In this paper, we build the data processing flow as "data acquisition-data analysis-information integration-comprehensive service" and sea ice business-oriented service mode. The framework can provide reference for the construction of sea ice comprehensive service and expert aid decision-making system in China.

\section{ACKNOWLEDGEMENTS}

This research was sponsored by the Special Fund for Marine Research in the Public Interest (GN: 201105016), the Foundation of Shandong Provincial Key Laboratory of Marine Ecological Environment and Disaster Prevention and Mitigation Foundation (GN: 2012013), the Young Foundation of North China Sea Branch of State Oceanic Administration (GN: 2015B09), and the Foundation of for Key Laboratory of Marine Spill Oil Identification and Damage Assessment Technology, SOA (GN: 201510).

\section{REFERENCES}

[1] Karvonen, J. 2012. Operational SAR based sea ice drift monitoring over the Baltic Sea. Ocean Science 8(4):473-483.

[2] William, A. G. \& Christopher, H. 2005. Climate Memory and Long-Range Forecasting of Sea Ice Conditions in Hudson Strait. Polar Geography 29(1)

[3] Wenyang, G. 2009. Sea ice forecasting system of United States Navy. Marine Forecasts 26(2): 103-109. 
[4] Scott, G. 2010. Towards Sea Ice Remote Sensing with Space Detected GPS Signals: Demonstration of Technical Feasibility and Initial Consistency Check Using Low Resolution Sea Ice Information. Remote Sensing 2(8): 2017.

[5] Shiway, W. W. 2014. Fatty acid and stable isotope characteristics of sea ice and pelagic particulate organic matter in the Bering Sea: tools for estimating sea ice algal contribution to Arctic food web production. Oecologia. 174(3): 699-712.

[6] Ning, W. 2011. The design of Bohai Sea ice detection system based on the MODIS images of remote sensing. Marine Forecasts. 28(1):33-38.

[7] Qiaozhen, L. 2007. Establishment and Application of an Information Extraction System About the Sea-Ice Area in the Bohai Sea. Marine Science Bulletin. 26(3): 105-111.

[8] Haitian, Zh. 2011. Satellite remote sensing of sea ice monitoring system in the Bohai Sea. Marine Forecasts.28(6): 55-59.

[9] Song, W. 2014. Design and implementation of Arctic Ocean sea ice satellite remote sensing information system based on Flex Viewer. Journal of Shanghai Ocean University.23(4): 623-628

[10] Shuo, W. 2013. Design Integrated Vehicle-borne System of Emergency Monitoring for Sea Ice Disaster. Marine Forecasts. 30(1): 71-77.

[11] Meng, Zh. 2005. Application of radar sea ice monitoring and numerical forecast technique to operation in the ice zone of Liaodong Bay. Journal of Dalian Maritime University. 31(1):73-76.

[12] Jingkun, X. 2006. The mission petroleum output system of tanker using radar monitoring and forecasting sea-ice in Liaodong Bay. Marine Environmental Science. 25(1) 76-79.

[13] Yaoqing, F. 2013. Design and implementation of automatic monitoring system of sea ice threat to the offshore oil platform. Journal of Safety and Environment. 13(6): 243-249.

[14]Conghua, C. 2013 Design and Realization of Numerical Sea Ice Forecast System Based on Data Marts. Computer and Modernization. (2): 123-129. 